\title{
FiguraÇões Do Monstro E O PROCESSO TRADUTÓRIO
}

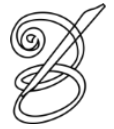 \\ Junia Barreto ${ }^{1}$ \\ (Profa. Adjunta do Departamento de Teoria Literária e Literaturas - UnB \\ Programa de Pós-Graduação em Estudos da Tradução - POSTRAD/UnB/Brasília/DF/Brasil \\ Programa de Pós-Graduação em Literatura - PÓS-LIT/UnB/Brasília/DF/Brasil) \\ junia.barreto@terra.com.br
}

\section{APRESENTAÇÃO}

$\mathrm{O}$

presente dossiê é fruto de algumas das discussões empreendidas no âmbito dos cursos de Tradução Literária e Tradução e Literatura dos Programas de PósGraduação em Estudos da Tradução e de Pós-Graduação em Literatura, ambos da Universidade de Brasília. Nos referidos cursos tratou-se de evidenciar e discutir a importância da tradução na formação da literatura, mais especificamente nas literaturas de origem latina, assim como possibilitar maior conhecimento de diferentes teorias e práticas da tradução literária. Além de incitar a reflexão sobre o lugar do tradutor no processo de tradução, procurou-se fomentar competências científicas e literárias necessárias ao ato tradutório, assim como exercitar a tradução literária de textos fonte escritos em francês e inglês, tendo como alvo o leitor de língua portuguesa do Brasil.

No centro de tal proposta, empreendeu-se a leitura de dois romances do século XIX, confrontadas a algumas de suas versões para o português: Frankenstein ou o moderno prometeu (1818), de Mary Shelley (original em inglês, Frankenstein: or the Modern Prometheus) e Notre-Dame de Paris (1831), de Victor Hugo (original em francês de mesmo título), nos quais se projetou um olhar crítico sobre a representação do monstro e da monstruosidade dentro dos textos.

A produção discente ao longo do curso se deu através de quatro tempos fortes: discussões em torno da história e do exercício da tradução no Brasil, objetivando as especificidades do século XIX; apresentação de um panorama das traduções da obra dos autores escolhidos, devidamente traduzidas em português do Brasil durante o século XIX; a prática da tradução e sua análise, sobre parte dos romances abordados; e a produção de uma reflexão crítica e científica (sob a forma de artigo) relacionando o tema central do curso, $a$ representação da monstruosidade, a uma determinada problemática suscitada a partir do 
corpus tratado no âmbito do ateliê de tradução realizado na etapa anterior.

Muitos foram os trabalhos de qualidade apresentados como resultado final dessa experiência, mas, infelizmente, figura neste dossiê apenas uma pequena parte dessa produção em torno das figurações do monstro e o processo tradutório. Agradeço àqueles que não puderem integrá-lo, mas que de alguma forma fomentaram e enriqueceram as discussões com sua participação e trabalhos produzidos: Amarílis de Anchieta, Henrique de Matos, Patrícia Costa, André Martins, Caroline Feital, Guilherme Santos, Beatriz Pimentel e Juliana Cecci.

As reflexões aqui expostas versam sobre os dois romances em questão: Frankenstein ou o moderno prometeu e Notre-Dame de Paris.

No ensaio de Jorgiana de Azevedo, "O horror de Frankenstein: uma reflexão tradutória", a autora empreende com maestria um estudo sobre o olhar da tradução em torno da imagética produzida acerca do personagem monstruoso em sua forma disforme, enquanto criatura produzida pelo cientista Victor Frankenstein.

Evidencia em suas análises como os tradutores, a partir de diferentes perspectivas, destacam aspectos diversos da narrativa de Shelley, investindo em determinadas 8 conformações psíquicas da narrativa, cujas escolhas norteiam a construção e a assimilação do monstro e da monstruosidade expressas no texto de chegada; monstro e a monstruosidade significando, então, diferentemente para o leitor da obra. A monstruosidade física da criatura em contraponto à monstruosidade moral do criador são torneadas e evidenciadas distintamente por cada tradutor e suas ferramentas, o que influi na produção e no entendimento do sentido do texto produzido pelo leitor. As escolhas e intervenções do tradutor corroboram também para a construção da própria atmosfera da trama, o que pode servir para caracterizar a narrativa enquanto produção inserida na literatura fantástica, na literatura gótica ou ainda na literatura de ficção científica.

A autora aponta também para a contaminação entre texto literário e texto fílmico, numa operação de tradução intersemiótica tão bem-sucedida que a mitologia literária que envolve a criatura não foi capaz de se desvencilhar da imagem da representação fílmica dos anos de 1930, personificada então pelo ator Boris Karloff e seu Frankenstein autômato e descomunal. Tal pujança alcançada no processo tradutório pela narrativa fílmica fez com que a criatura tomasse o nome do criador e se transformasse em um ícone das letras, das artes e da cultura.

Em seu artigo "A tradução e a criação de monstros: uma analogia entre o ato tradutório e o monstro e sua criação em Frankenstein", Cândida Laner Rodrigues discute a monstruação 
do processo tradutório, associando o personagem da criatura monstruosa à figura do tradutor monstro, assim como a monstruosidade implícita ao próprio processo da tarefa tradutória, visto que a tradução seria geradora de monstros. Para tal, utiliza-se de uma leitura atenta do ensaio de Walter Benjamin, A tarefa do tradutor, em consonância com a leitura do romance de Shelley, questionando em que medida seria possível comparar a criação do monstro com o ato tradutório, e quais seriam os aspectos mais relevantes para empreender tal analogia. A autora considera que autor do original assumiria o lugar de Deus, criador supremo, enquanto o tradutor permaneceria desprotegido diante do resultado final da tarefa tradutória, angustiandose diante da consciência do fato de que "o mesmo é apenas um dos possíveis reflexos do conteúdo presente e implícito do original".

Recupera ainda a associação histórica do babelismo e da integração das línguas ao processo de monstruação (o devir monstro, o tornar-se monstro, a fabricação do monstro). $\mathrm{O}$ cientista Victor Frankenstein, enquanto criador da criatura, a partir do ajuntamento de partes e restos, seria o tradutor de um original que é o próprio ser humano. Tradutor e cientista se assemelhariam então em suas respectivas empreitadas.

A sobrevida do texto que lhe assegura sua tradução estabelece que para o original permanecer vivo, ele precisará ser continuamente traduzido através dos tempos. O livro necessitando de leitores para se perpetuar e garantir uma sobrevida, a criatura precisando do próprio criador, Victor Frankenstein, para garantir sua continuidade e a perpetuação de sua espécie. Todo tradutor daria vida então a um monstro diferente, dependendo de sua concepção de tradução, de sua inserção num tempo e num espaço próprios, de suas interpretações dos sentidos do texto. A autora advoga pela possibilidade de o tradutor se colocar no lugar do criador Frankenstein, mentor de um árduo trabalho, assim como o é a tarefa da tradução.

Jocileide Silva, em seu artigo "As figuras de linguagem e suas traduções em NotreDame de Paris: a representação da monstruosidade no espaço obscuro da masmorra", empreende um estudo no campo da estilística, em torno do uso feito por Victor Hugo, em seu romance, de figuras de linguagem/ou de estilo (a metáfora, a antítese e a gradação), para auxiliar na caracterização de um espaço na trama, reconhecidamente monstruoso e infernal. Tal espaço se constitui de lugares como a própria catedral, o cadafalso, o cárcere, os porões, as torres, os esgotos, becos, subterrâneos, etc.

A autora se interessa e investiga pertinentemente sobre a manutenção e a adequação da conservação de tais figuras no texto de chegada. Interessa-se por atestar ou não sobre a preservação dos mesmos sentidos produzidos no processo tradutório, na passagem do texto 
fonte ao texto alvo, garantindo ou não o mesmo efeito do monstruoso.

Em suas discussões traz à tona conceitos plantados na filosofia de Edmond Burke e Paul Ricœur, assim como se apoia em trabalhos da linguística e da estética. A autora aborda a complexidade da tarefa de tradução concernente às figuras de linguagem, visto que pode significar "uma garantia de ganhos para a língua alvo, porém, algumas vezes de perdas, pois a tradução pode não conseguir equivalentes para repassar o mesmo efeito proposto no texto fonte", acarretando uma possível intraduzibilidade, na perspectiva de Ricœur.

Aponta as competências necessárias acerca das figuras de linguagem para o processo tradutório e compara trechos do texto de Hugo ao resultado obtido na tradução para a língua alvo, investigando a possibilidade de manter a particularidade das descrições do espaço monstruoso. Destaca, por fim, a importância do bom manuseio das figuras de linguagem no processo de tradução para a construção, na língua alvo, do rico imaginário presente no texto hugoano.

Encerrando este dossiê, o estudo de Dennys da Silva Reis, "Notre-Dame de Paris: terminologia específica em texto literário?", se interessa também ao campo da linguagem, 10 considerando que o uso de terminologia específica dentro do texto literário constitui-se numa tarefa monstruosa para o trabalho do tradutor. A presença de tal terminologia específica a domínios distintos e tantas vezes complexos (evocando minúcias da ornitologia, da mineralogia, por exemplo) requer um trabalho de pesquisa terminológica da parte do tradutor, implicando assim uma monstruação tradutorória. Este processo de monstruação se traduziria em ações complexas e específicas vivenciadas pelo tradutor, no intuito de preservar a terminologia (discurso/estilo autoral), ou mesmo parte dessa terminologia, e assim bem exercer sua tarefa de tradutor.

No caso de Victor Hugo, Dennys Reis ressalta que além do hibridismo intrínseco ao texto em si, o hibridismo do texto hugoano é marcado pelo excessivo conhecimento terminológico do autor, o que representa um complicador a mais na tarefa da tradução. $\mathrm{Na}$ operação tradutória torna-se então necessário manipular, além dos conhecimentos sobre o texto literário, os conhecimentos contextuais, discursivos e linguísticos, o saber terminológico e seu léxico especializado, envolvendo muitas vezes técnicas e práticas científicas. Nesse estudo, a autor trata da recorrência de terminologia específica presente em um dos capítulos do romance Notre-Dame de Paris, em torno da arquitetura, da vida eclesiástica e do vestuário dos personagens.

Resgata também a antiga associação existente entre monstruosidade e tradução, 
chegando à contemporaneidade e à ideia da prática antropofágica implícita à teoria da tradução, valendo-se dos estudos de Célia Magalhães sobre as teorias do tradutor e poeta Haroldo de Campos, cuja obra traduzida constitui-se de partes e fragmentos de outros textos, portanto, à imagem da metamorfose que caracteriza o monstro. Seria possível então pensar numa "teoria frankensteiniana da tradução". A prática de Campos recriando, transcriando, segundo Reis (apud MAGALHÃES, 1998, p. 25-26), “tomando um texto concreto em língua fonte e reconstituindo-o em língua de chegada, como no caso da aberração criada por Victor Frankenstein, construída a partir de partes distintas de corpos humanos até se tornar um teratismo".

As figurações de monstros se comunicam neste dossiê e nos dois romances oitocentistas aqui evocados. A concepção de monstruosidade no século XIX, segundo Halberstam, nos remete às marcas da violação racial ou da espécie - podemos então pensar na violação da espécie humana com Frankenstein, considerando o monstro enquanto "tecnologia" que incorpora uma multiplicidade de medos, cuja forma e contorno é proporcionada pelo leitor, pois o monstro, em sua forma, é a representação do "jogo de leitura e escrita, re-escrita e conto, conto e interpretação" (J. Halberstam).

Também é intrínseca a relação existente entre a monstruosidade, o monstro e o processo tradutório, considerando-se a noção de monstro e de monstruosidade nesse processo, segundo propõe Magalhães (1998), enquanto construção discursiva, representando valores culturais específicos. O monstro,

\begin{abstract}
como representação da teoria da tradução faria parte de uma estratégia discursiva que leva a articular as diferenças radicais entre os modos de ser radicalmente contrários, tornando possível renomear, transformar e apropriar, num movimento que vai da identificação para a alienação total: confunde-se o eu com o outro num primeiro momento para, em seguida, transformar-se o outro em estranho que se pode destruir, como é o caso do monstro gótico Frankenstein, ou incorporar, exemplo do monstro modernista, o antropófago.
\end{abstract}

\footnotetext{
${ }^{1}$ Currículo Lattes em:< http://buscatextual.cnpq.br/buscatextual/visualizacv.do?id=K4796468U6>.
} 